\title{
Dos and don'ts of scholarly publishing (part II)
}

\author{
Hercules E. Haralambides ${ }^{1}$
}

Published online: 12 July 2018

(C) Springer Nature Limited 2018

\section{Introduction}

This editorial is a follow-up to the one that appeared in $2016,{ }^{1}$ and it has been written with young Chinese (and not only...) researchers in mind: a growing body of both our readership and of our contributing authors. The article thus addresses mostly the junior academic, or the one on a career path/tenure track. Senior academics are familiar with all that follows, of course, but their advice in improving our procedures, as well as my role as $\mathrm{EiC}$ of MEL, would be more than welcome.

\section{Your subject}

Be knowledgeable about the subject you want to write about (if possible, co-author your paper with industry executives). If you write about a ship or a port or a terminal, make sure you have actually seen one; MEL is an applied journal. If visiting your subject is difficult, and often it is, do keep in mind that there are hundreds of good videos around, freely accessible on the internet. When you thus talk about a 'bay', or an 'apron', or a 'twist lock', it is important that you have seen one and understand how it works. Shipping and ports, in particular, are rather practical disciplines, often run by very successful albeit comparatively less-educated people with a notable disdain for the academia: ${ }^{2}$ with your paper, try to bridge this gap and allay

\footnotetext{
${ }^{1}$ Haralambides, H.E. (2016) 'Dos and don'ts in scholarly publishing' (Part I). Maritime Economics and Logistics, 18(2), 101-102.

2 A very important econometrician once approached the port of Rotterdam telling them: "give me the data and I will solve all your problems". They are still laughing at the Port of Rotterdam.
}

Hercules E. Haralambides haralambides@tamu.edu

1 Texas A\&M University, College Station, Texas, USA 
their misgivings. In the same vein, while preparing your paper, do not read only scientific works; familiarize yourself with the professional world around your subject, including newspapers and sectoral Press. ${ }^{3}$

Before you submit your paper to a journal, distribute a working paper and invite comments from colleagues and business contacts. Even better, organize a staff seminar and present your paper. Don't be afraid to do that. This is the best advice I can give you. Most likely, upon submission, your editor will also ask you: "have you shown your paper to anyone before submitting?". MEL, same as many other applied journals, does not publish 'exercises on paper', nor research no one has asked for, or research that addresses questions that exist only in the author's mind.

\section{Which journal?}

Unless you already have considerable publishing experience and are familiar with the journals of your sector, choosing the right journal (and editor...) is no easy job. The first question you should ask yourself is 'for whom am I writing?'. Are you addressing a broader audience (business; government; policy-making) or rather some technical academics (Operations Research/Econometrics)? This should also determine your writing style. In other words, is your contribution to be found in the paper's methodology or in its policy/business ramifications? If your contribution is methodological, submit to an OR/econometrics journal. If, however, your contribution is in your paper's "policy/business ramifications", the technical discussion (as well as math) should be limited to a bare minimum in the main text; a good reference provided for the interested reader; and the methodology placed in an appendix. There, the detail should be sufficient (together with your data) so that your model(s) can be easily reproduced by others.

Most journals don't take well to declarations of confidentiality (e.g. the company name cannot be mentioned, or the data cannot be submitted due to confidentiality, etc.). Your editor will ask you to explain the reasons for the confidentiality and if they are not valid/strong probably your paper will be rejected. In the same vein, for papers based on surveys, be prepared to disclose the names of the interviewees if requested by the editor.

Read many issues (abstracts) of the proposed journal and try to understand its Aims and Scope: is it for you? Does it publish papers similar to yours? This understanding is crucial to avoid a disappointing rejection. If in doubt, it is not a bad idea to send an abstract to the journal's editor and ask; most editors will be happy to enlighten you. Always submit to a journal with a Thompson Reuters impact factor. If your proposed journal does not report one for the previous year, inquire with the

\footnotetext{
3 My good friend, colleague and schoolmate (Cardiff) Tae Woo (Paul) Lee was once recounting me a story where, at a certain conference, a young researcher was presenting a very elaborate model of liner shipping network optimization. At the end of his presentation, Paul asked him what were the size and the speed of the ships he was assuming; the researcher had no answer... Interestingly, the paper was voted as the 'best conference paper'.
} 
EiC as to the reason why. Consult JCR (journal citation reports) for journals that may have been suspended and/or not given an impact factor.

Your editor is probably a senior colleague; treat him as such and write to him personally, rather than asking your secretary (or a student assistant) to submit the paper. If you do not have time for him, perhaps he and his referees may not have time for you.

\section{The cover letter}

Your Cover Letter (CL) is very important and it is an immediate 'sample' of your paper. By reading your CL, your editor will get a first idea (and there is never a second chance for a good first impression) about the quality of your paper, as well as about your skills and publishing experience.

Do not duplicate your abstract in the CL; rather, and just in a couple of lines, try to convince your editor why publishing your paper has merit and it is a good idea.

Give full details of all co-authors, including their function and designation.

Mention some key publications of each co-author, in the English language, and published in an English medium. If possible, quote papers in refereed journals. Usually, editors have a lesser interest in conference proceedings or book chapters.

Declare (no) conflict of interest and your acknowledgements (if any).

Have a look at the MEL website to see how a good CL should look like.

\section{Co-authorship}

A common mistake, usually made by junior researchers, is to try to publish as a sole author. It is a mistake because a senior co-author, e.g. your supervising professor, will bring you citations. This should be your real objective and not to see your name in print, albeit with zero citations. Our reading time becomes scarcer and scarcer, while at the same time, we are drowning in information and new publications. Many people will read a paper co-authored by a famous professor, but very few (if any) will read one by a relatively unknown young researcher, no matter how good her paper might be.

A senior co-author brings another benefit onboard: most probably, he is also a seasoned writer and, as I discuss below, writing is an 'art' which takes years to master. A common reason for rejecting a paper is poor English and writing style, notwithstanding how good the paper might be content-wise.

Some authors of joint papers are often quite keen to appear as 'corresponding authors', believing that readers will assume that she is also the main author. This is not true. MEL for example does not report corresponding authors and when it does it makes it clear that a 'corresponding author' is just the one who exchanges emails with the EiC. As regards author order, in MEL and many other journals, most of the time, co-authors appear in alphabetical order of family name. MEL assumes that all co-authors are equally and indistinguishably responsible for the paper. If this is not 
the case, and thus authors require a different author-order, the journal may need to explain 'respective roles' in a headnote.

Outside our triennial $\mathrm{PhD}$ competition, MEL is rather cautious in publishing papers co-authored by PhD students, unless the supervising faculty member explains clearly the respective roles in the Cover Letter. In this light, and before submitting, the graduate student should make sure that her co-author is a 'real' co-author and not one who has just lent his name; your editor will see this immediately, and in most cases, this will lead to a negative decision.

\section{Writing is and art}

The minute a student assistant (SA) sits behind a computer, he often believes he is ready for the Nobel Prize! This is particularly true if the SA is a skillful and talented mathematician, trying to apply his skills to a relatively under-researched problem in humanities and social sciences.

However, it is one thing to come up with good results, as well as prepare nice tables and graphs, and another thing to write a good paper. Differently, it is one thing to put words in a sentence, and another to compose a sentence conveying a clear message in a structured and impactful way.

Write succinctly. Use short sentences and avoid wordiness and repetition. If your English is good, do not try to show it off; our discipline is a practical one; not literature. Avoid the superlative and words like 'fabulous', 'tremendous', etc., which are quite common in expressions of many countries.

If you are not native English speaker, use the services of an English editor prior to submitting. There are many of them around, from the prestigious ones of international publishers, to one-person internet-based companies. Their prices vary greatly, ${ }^{4}$ ranging from $\$ 100$ to $\$ 500$ per paper or even more. If necessary, seek advice because what matters is not price but price-quality, as well as the amount of work your paper requires (which can range from light grammatical improvements to actual 'rewriting').

Finally, write with your readers in mind and not yourself or your colleagues. Your readers may not know as much as you do, and thus you shouldn't take too many things for granted. A part in your introduction should be dedicated to providing your reader with all the information necessary to understand your paper.

\section{Title and abstract}

Think of an "appetizing" title that should be as brief as possible but also representative of your contents. A good title, consisting of carefully selected, albeit 'hot', words is your ticket to citations. I have come across many papers of mediocre content but with hundreds of citations, just because the author was smart enough to

\footnotetext{
${ }^{4}$ I made a mistake: I used superlative, i.e. 'greatly' rather than, say, 'significantly'.
} 
choose the right words in the title. Unfortunately, life is not always serious and more often than not-and for longevity- it shouldn't be taken too seriously either. ${ }^{5}$

To the extent possible, your Abstract (200-250 words) should be written in nontechnical language, aimed at the general reader, and it should not include references or footnotes. This is the most important part of your paper, and the one that everybody will read; it needs to convince the reader that the paper is worth reading. In non-technical language, explain to the reader why you wrote this paper; who has asked for it; what do you add to existing knowledge; what is your methodology; what are your main conclusions. Remember: your abstract is something very different from your introduction, which will probably follow. Thus, do not duplicate.

\section{Literature review}

Long literature reviews are usually not appreciated by readers. This does not mean you should neglect important contributions, but instead of discussing each work individually (which might involve some repetition), try instead to discuss a theme or an issue, and put in parentheses the authors who have dealt with it.

When you discuss a work, don't mention only what the author did but, more importantly, discuss his results and how these impact your own paper. This is the reason you quote a work, and not just to show that you have read a lot. In this sense, your literature review should comprise works relevant to yours in a narrow sense (e.g. when you optimize stowage on a ship, don't review papers on yard stacking optimization, although both subjects may have used the same methodology).

Identify top researchers (and top papers) and stay away from the trivial ones (no citations). Most definitely, don't build your paper on trivial publications. Finally, your references should be as recent as possible, in English, and easily traceable.

\section{Tables and figures}

Spare no effort to produce high quality, professional, tables and figures. If you don't have this experience, seek advice or help from a graphic designer. Tables and figures are the 'mirror' of your paper, and they show to the reader the degree of diligence and amount of investment you have put into the drafting of your paper. An impressed referee my feel obliged to reciprocate and invest in your paper as a quid pro quo.

Tables and figures should be self-explanatory; thus, you should not repeat/discuss them (a lot) in the text.

It is easy to create lots of tables and figures; however, readers are not impressed by their number. Often, a table or a figure is redundant, just taking up journal space which is very expensive. If you can say something in conventional sentences, instead of

\footnotetext{
5 I was once talking to the EiC of a top economics journal. With a big smile on his face I remember him telling me that $75 \%$ of his rejections were ending up in two competing journals which, interestingly, had a much higher impact factor than his own!.
} 
a table or figure, do so. Same is true for bullet lists: if you can avoid them, and structure your text in the usual way, do so.

\section{Peer review}

Once your paper is submitted, the EiC will decide if it should be considered further, or returned as not fitting into the journal's aims and scope. ${ }^{6}$

In the former case, the paper is forwarded for refereeing. Referees will have to do the same test: i.e. advise the EiC on Outright Rejection (ORR), or proceed with refereeing. Instances where ORR is common are "exercises on paper"-mostly of the optimization/simulation type-with little or zero practical relevance. Other ORR cases consist of "attempted solutions" to problems that exist (or created) only in the author's mind; i.e. solutions no one else has asked for. Finally, a number of editors feel that an additional reason for an ORR might be their expectations on a paper's impact (citations); something not completely uncorrelated with the author's prior publishing experience.

In the case the referee decides to review your paper, he becomes your friend and your advisor (at least in MEL); thus treat him nicely! His objective is to help you improve your paper. He will be constructive, therefore, and won't ask you to do impossible things, e.g. re-estimate a model. If he wanted to do that he would have rejected the paper at the beginning (ORR).

Good and reliable referees are difficult to find, an 'endangered species' I would say, and we treat them with a lot of understanding as regard their time and busy agendas; the refereeing process of a serious journal is a lengthy one. If you look for 'quick and dirty' refereeing, there are plenty of journals around, but think of your reputation: Would you submit again to a journal whose only comment was "this is a good paper and we accept it"?

\section{Conclusions}

For journals like MEL, the ramifications of your results for business and society are more important than figures and percentages.

Start from your most important results and move down to the less important.

Same as in the Abstract, Conclusions should be written in non-technical language, to the extent possible. As most people will also attempt to read your conclusions, they should be written in 'perfect English'; if necessary, seek advice.

Conclusions are 'conclusions' and although you may want to summarize the paper (legitimate) you should not introduce aspects of it, or new ideas, which have not been discussed in the main text. Also, try not to include references in your conclusions.

Discuss the limitations of your paper.

Good luck with your research!

\footnotetext{
${ }^{6}$ As said above, this is the 'research' you should be doing before submitting.
}

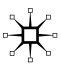

